\title{
THE GOLDEN LAB AND THE COYOTE
}

\section{A. SAAS, 230 Athabasca W., Moose Jaw, Saskatchewan. SOH 2B9}

Spring was trying to arrive, forcing out the last days of Old Man Winter by warming up the hillsides and ravines. The sun seemed extremely warm and inviting today even though the odd snow bank was still trying to make a last desperate attempt to hang on for its life. Not being able to resist an invitation to the first call of spring, my dog Sam and I prepared for a brisk walk in the nearby valley.

I packed a thermos of coffee, a book to read in the warm sun, some dog biscuits and a litre of water for the dog. These we would enjoy at the picnic tables at the half way point of our walk.

The walk began after a 10 minute drive to get out of the city. It was great, tramping through mud and dry areas and a mixture of both. We stopped often on this first glorious walk of spring to make certain that we enjoyed everything around us.

The squawk of the early arriving Canada and Snow Geese let all around them know that they were messengers of spring bringing the sun and the warm winds. In tune with the geese was the quacking of the pintail and mallard ducks attempting to set up territory. The early chokecherry buds looked tasty on the trees as well as the old rose hips still left from last year. They occasionally whispered to Sam to come on over and leave his mark as other animals that passed by had done. No place could be better than the open air in early spring.

After an enjoyable walk of five medium hills and five ever so long, tall and steep hills we finally made it to the picnic area and fell exhausted ont benches of the picnic tables.

As quick as a wink the first $\mathrm{Cl}$ coffee was drunk up and Sam ha water. This was our reward for our walk. The dog biscuits were qu I eaten by Sam and with the second, of coffee came the signal that we c/ now sit back and relax for a whili course, before Sam could rela: usual sniffing of everything arour $u$ had to be done. Then as the sill diminished he came over and $s \in ?_{1}$ down for a quiet nap in the sun. " book that I was reading took all ss sures away from my mind and stil is slowly settled in.

In the quietness of the easy blowing in the trees and the $s$ flowers trying to bud, we became pletely enwrapped in our relaxati

I was abruptly brought aroul reality by a strange grunting sour my dog. I hollered at him for so $r$ interrupting my solitude. He sto but out of the corner of my eye I see him crawling on his belly. I qu continued to read and was almost solution to the mystery when Sam that same weird grunt sound aga was a sickening sound so I had tc up to see what he was up to. No had crawled about 50 yards from 1 he was and all this distance on his as the slide marks in the soft soil cated. There, ahead of him, coyote doing the same type of cra as what Sam did. I stopped and wa in awe. There were both animals ing towards each other making st grunting sounds. I got frightent myself and Sam as he got up fro 


\section{HYBRID DEER}

The winter of 1984 - 1985 was a fairly severe winter and a deer feeding program was instituted. Having a fair number of deer around (mostly Mule Deer and some White-tailed) took part in this program. It was surprising how soon the deer knew feed was being put out for them at evening and morning chore time. As if by magic at $8: 30$ in the morning and 4:30 in the afternoon deer appeared out of the tree shelterbelts. Those that had gone back to the riverbreaks were coming on the run, as if they were racing to see who could get there first.

When spring weather arrived the deer spent most of their time in the riverbreaks, and much less time at the farm. In the fall of $1985-1986$, when the first bad weather arrived, a small herd came in and were searching for food in the area that they had been fed the previous winter.

I was surprised to see that two of the Mule Deer does had White-tail fawns nursing on them. One had two and the other had one. These were soon weaned but stayed close to mothers until spring.

The next fall, 1986 - 1987, they back again, but the mothers had Deer fawns. Two of the previol spring White-tails were bucks. were quite independent, the th doe, followed her mother and si The fall of $1987-1988$ the samt were around, except for one White-tail bucks. It had either si away or was taken during the hi season. This season of 1988 the de back again and the surviving $b$ now a proud specimen and th arrived with a youngster.

I am positive that these three de were nursing on Mule Deer d 1985 - 1986 are White-tail and Deer crosses. It is hard to believ Mule Deer would adopt other Deer let alone those of another $\mathrm{SF}$ We have had a White-tail buck as ing with the Mule Deer for $s$ years. - Sig Jordheim, White Bea atchewan. SOL $3 \mathrm{LO}$
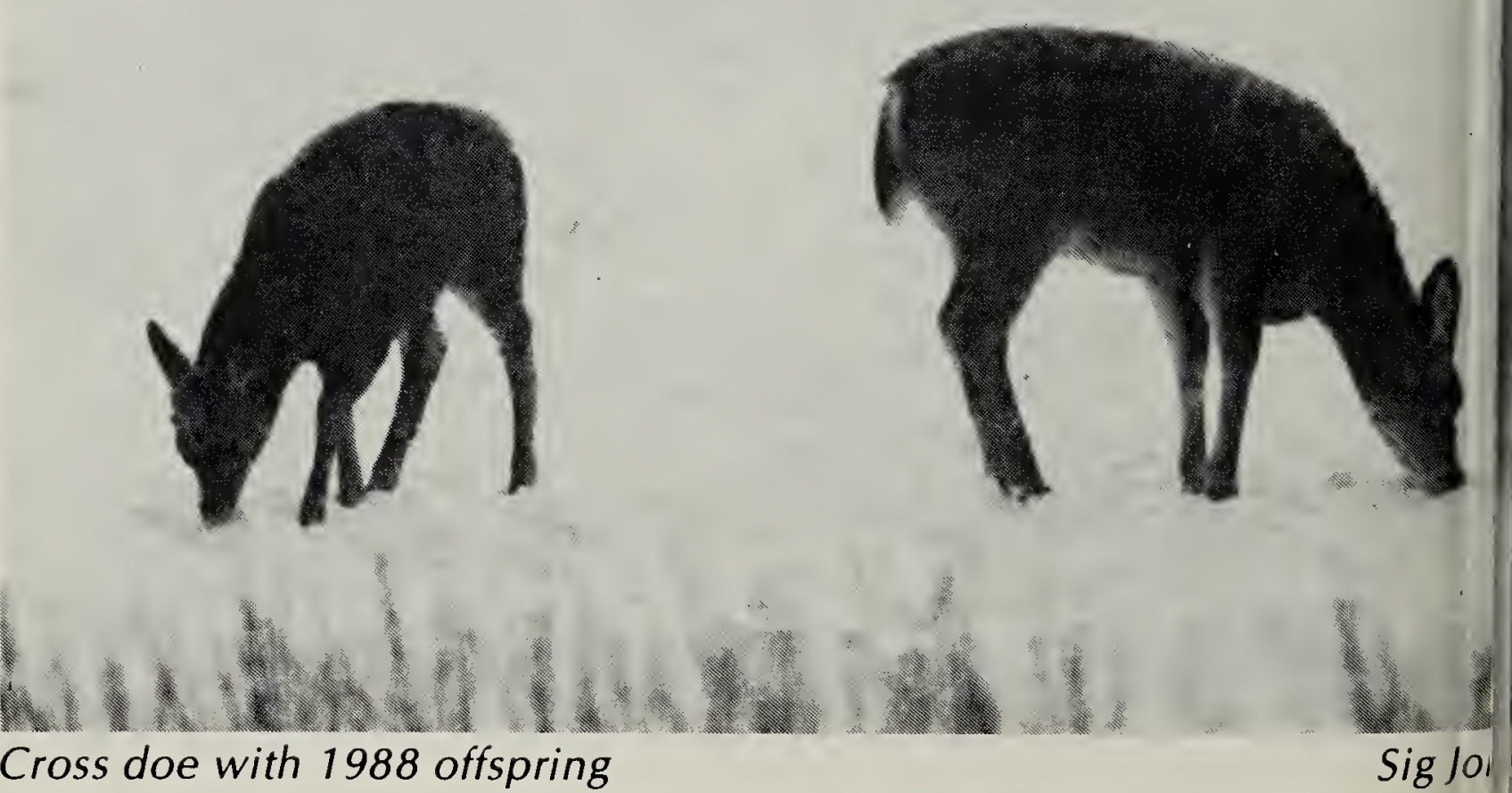

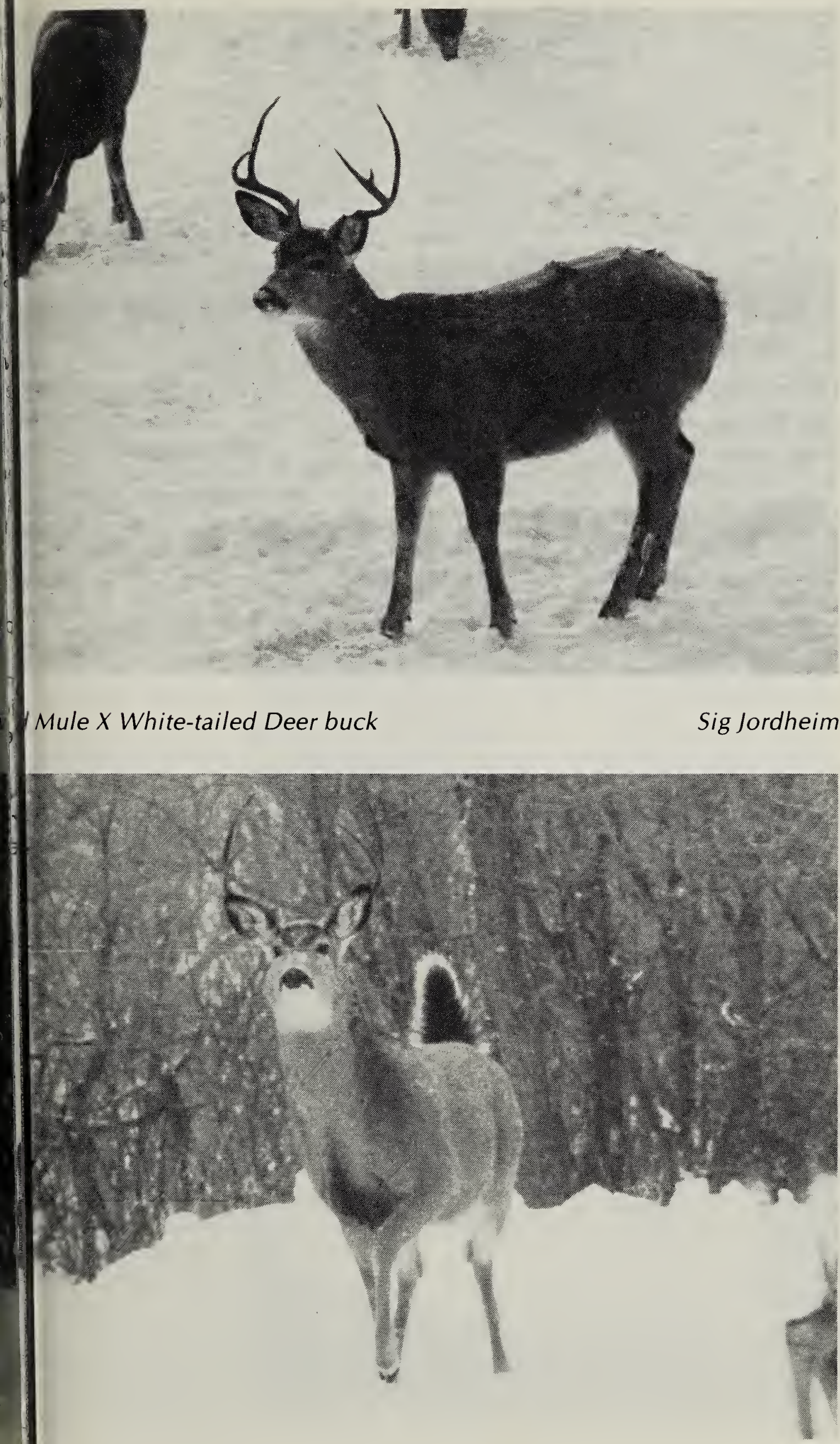